\title{
One-Pot Synthesis of 1, 4-Dihydropyridines in PEG Under Catalyst-Free Conditions
}

Jing Lv

Shandong Provincial Key laboratory of Ocean

Environment Monitoring Technology

Shandong Academy of science Institute of

Oceanographic Instrumentation

Qingdao China

jissrain@163.com

Liang Jun

Blue Economic Development Center of Qingdao West

Coast Area

Qingdao China

1j921j@163.com

\section{Xiangfeng Kong}

Shandong Provincial Key laboratory of Ocean

Environment Monitoring Technology

Shandong Academy of science Institute of

Oceanographic Instrumentation

Qingdao China

kxf1985@163.com

\author{
$\mathrm{Lu} \mathrm{Cao}$ \\ Shandong Provincial Key laboratory of Ocean \\ Environment Monitoring Technology \\ Shandong Academy of science Institute of \\ Oceanographic Instrumentation \\ Qingdao China \\ icecream10@163.com
}

Ying Zhang

Shandong Provincial Key laboratory of Ocean

Environment Monitoring Technology

Shandong Academy of science Institute of

Oceanographic Instrumentation

Qingdao China

zy9951132@126.com

\author{
Shuwei zhang \\ Shandong Provincial Key laboratory of Ocean \\ Environment Monitoring Technology \\ Shandong Academy of science Institute of \\ Oceanographic Instrumentation \\ Qingdao China \\ zhshwei_123@163.com
}

\begin{abstract}
A simple, inexpensive, and efficient one-pot synthesis of 1,4-dihydropyridine via Hantzsch reaction was achieved in good to excellent yields under catalyst free conditions by using PEG400 as solvent. In this reaction, PEG-400 was used as the solvent, which has such advantages: absolutely nontoxic, inexpensive, thermally stable, recoverable and easy to dispose in the reaction. And the corresponding products: 1,4-Dihydropyridine derivatives are very important in organic chemistry and medicine industry, by the using of PEG, the yields of the reaction were all very high(most above $95 \%$ ). Finally, as to the inexpensive of PEG-400 and the high yields of the reaction, also because of the easy-treated procedures, this kind of reaction could be easier to produce in industrial. So, Polyethylene glycol offers a convenient, inexpensive, non-ionic liquid, non-toxic and recyclable reactions .
\end{abstract}

Keywords-1,4-Dihydropyridines, Hantzsch Multicomponent synthesis, PEG400, Catalyst free.

\section{INTRODUCTION}

1,4-Dihydopyridines (1,4-DHPs) have received considerable attention because of their significant biological activitie. ${ }^{1}$ The well-known 1,4-DHPs antagonists are among the most widely used drugs for cardiovascular diseases. ${ }^{2}$ And these simple heterocyclic scaffolds have also been found possessing a wide range of other pharmacological activities ${ }^{3,4}$ and playing important role in chemical delivery systems. ${ }^{5}$ As several different strategies are presently available for the synthesis of 1,4DHPs, multicomponent reactions are recognized as the most powerful and facile tactic in term of providing structurally diverse 1,4-DHPs. ${ }^{6}$ The most classical multicomponent synthesis of 1,4-DHPs involves the onepot condensation of an aldehyde, ethyl acetoacetate and ammonia in either acetic acid or refluxing alcohol. However, yields of 1,4-DHPs obtained from Hantzsch method are generally low in most cases, particularly when aliphatic and unsaturated aldehydes were used. Although numerous modified methods have been reported, ${ }^{7}$ many of them suffer from drawbacks such as harsh reaction conditions, low yield of products, expensive catalyst, cumbersome workup procedures or long reaction time. Therefore, it is still desirable to develop efficient catalyst system for the one-pot synthesis of 1,4-dihydropyridines, better in the manner of mild conditions with recyclable resources as well as good tolerance to acid-sensitive functional groups. 
PEG and its monomethyl ethers are inexpensive, thermally stable, recoverable and nontoxic media for a broad range of different reactions, ${ }^{8-9}$ However, this kind of environmentally benign media have not been yet used for the synthesis of 1,4-DHPs via Hantzsch reaction.

\section{EXPERIMENT}

In continuation of our interest on PEG organic reactions, we wish to report herein the one-pot synthesis of 1,4-Dihydopyridines by Hantzsch reaction using various aldehydes, ethyl acetoacetate and ammonium acetate in the presence of PEG-400 under catalyst-free conditions (Scheme 1).
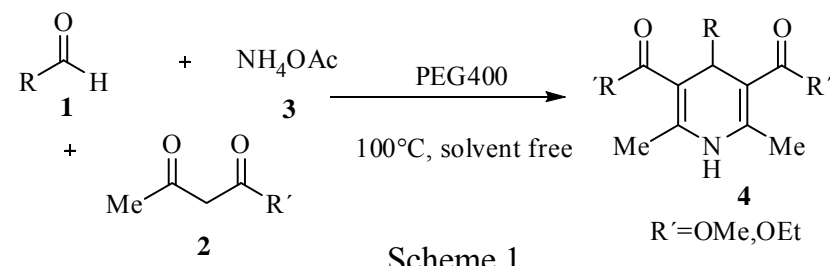

In a beginning, the reaction of benzaldehyde, ethyl acetoacetate and ammonium acetate in a $1: 2: 1$ ratio was performed by stirring in $0.4 \mathrm{~g}$ PEG-600. The product was obtained by recrystallization of the crude product from anhydrous ethanol after reaction time of $10 \mathrm{~h}$, and provided the yield of $60 \%$. Several kinds of PEGs were then investigated for this model reaction, and the corresponding results were showed in Table I. It was found that PEG-400 was the best media for the reaction.

TABLE I.. Effect of different kinds of PEGa

\begin{tabular}{|c|c|c|c|}
\hline Entry & PEG & Time/h & Yield $(\%)^{b}$ \\
\hline 1 & PEG-200 & 4 & 75 \\
\hline 2 & PEG-400 & 4 & 93 \\
\hline 3 & PEG-600 & 4 & 82 \\
\hline 4 & PEG-800 & 4 & 80 \\
\hline 5 & PEG-1000 & 4 & 76 \\
\hline 6 & PEG-2000 & 4 & 70 \\
\hline $\begin{array}{l}{ }^{a} \text { Reactio } \\
\text { ethylace }\end{array}$ & $\begin{array}{l}\text { tions: benzalde } \\
\text { te }(2 \mathrm{mmol}), \mathrm{P}\end{array}$ & $\begin{array}{l}\mathrm{nmol}), \mathrm{NH} \\
0.8 \mathrm{~g} \text { ), at }\end{array}$ & $(2 \mathrm{mmol})$ \\
\hline
\end{tabular}

With the optimized experimental conditions, various substituted aldehydes containing either electron donating or withdrawing groups were smoothly converted to corresponding 1,4-DHPs with excellent yields in the presence of PEG-400. The results are summarized in Table II. Both ethylacetoacetate and methylacetoacetate also smoothly reacted with aldehydes and ammonium acetate under standard reaction conditions. However, the yields of the products $4 \mathrm{e}$ and $4 \mathrm{~m}$ are slightly lower than other entries probably due to thee steric hindrance effect of the ortho-OH in the structure. All the products were characterized by comparing their physical and spectral (IR and $1 \mathrm{HNMR}$ ) data with corresponding data reported in literature.

TABLE II PEG-promoted synthesis of 1,4-dihydropyrimidinones under solvent-free conditions

\begin{tabular}{llllll}
\hline Entry Product & $\mathrm{R}$ & $\mathrm{R}^{\prime}$ & Time/h & Yield $(\%)^{b}$
\end{tabular}

$\begin{array}{llllll}1 & 4 a & \mathrm{C}_{6} \mathrm{H}_{5} & \text { OMe } & 4 & 95\end{array}$

$\begin{array}{llllll}2 & \text { 4b } & 4-\mathrm{CH}_{3} \mathrm{OC}_{6} \mathrm{H}_{4} & \mathrm{OMe} & 4 & 99\end{array}$

$3 \quad 4 c$

$$
\text { 4- }
$$

$\begin{array}{cccccc}4 & \mathbf{4 d} & 4-\mathrm{HOC}_{6} \mathrm{H}_{4} & \mathrm{OMe} & 3.5 & 97 \\ 5 & \mathbf{4 e} & 2-\mathrm{HOC}_{6} \mathrm{H}_{4} & \mathrm{OMe} & 4 & 83 \\ 6 & \mathbf{4 f} & 4-\mathrm{ClC}_{6} \mathrm{H}_{4} & \mathrm{OMe} & 3.5 & 93 \\ 7 & \mathbf{4 g} & 4-\mathrm{NO}_{2} \mathrm{C}_{6} \mathrm{H}_{4} & \mathrm{OMe} & 3.5 & 93 \\ 8 & \mathbf{4 h} & 2-\mathrm{Furyl} & \mathrm{OMe} & 0.5 & 99 \\ 9 & \mathbf{4 i} & \mathrm{C}_{6} \mathrm{H}_{5} & \mathrm{OEt} & 4 & 93 \\ 10 & \mathbf{4 j} & 4-\mathrm{CH}_{3} \mathrm{OC}_{6} \mathrm{H}_{4} & \mathrm{OEt} & 4 & 98\end{array}$

4

$4 \mathbf{k}$

$$
4-
$$

41

$\left(\mathrm{CH}_{3}\right)_{2} \mathrm{NC}_{6} \mathrm{H}_{4}$

OEt 4

96

13

\section{$4 m$}

$4-\mathrm{HOC}_{6} \mathrm{H}_{4}$

OEt

4n

$2-\mathrm{HOC}_{6} \mathrm{H}_{4}$

$\mathrm{OEt}$

$$
4
$$

$15 \quad 40$

$$
\text { 4- } \mathrm{ClC}_{6} \mathrm{H}_{4}
$$

$\mathrm{OEt}$

16

$$
\text { 4- } \mathrm{NO}_{2} \mathrm{C}_{6} \mathrm{H}_{4}
$$

OEt

$4 p$

OEt

0.5

98

\footnotetext{
${ }^{a}$ Reaction conditions: aldehyde ( $\left.1 \mathrm{mmol}\right), \mathrm{NH}_{4} \mathrm{OAc}(3 \mathrm{mmol}), \beta-$ dicarbonyl compound (2 mmol), PEG-400 (0.8 g) at $100^{\circ} \mathrm{C}$. ${ }^{b}$ Isolated yields.
}

To investigate the effect of $\mathrm{PEG}$, the model reaction was then performed by heating at $100{ }^{\circ} \mathrm{C}$ for $2 \mathrm{~h}$ in the absence of PEG. It was found that no reaction occurred, indicating that PEG was an essential promoter for this reaction. In addition, we also studied the PEG promoted Hantzsch condensation of benzaldehyde, ammonium acetate and ethyl acetoacetate in the presence of various solvents, such as water, acetonitrile, and toluene $(1 \mathrm{ml})$. These results are presented in Table III. According to these results, it is clear that in the presence of these additional 
solvents, the yields of 1,4-dihydropyrimidine derivatives were found comparatively lower.

TABLE III Effect of different solvents ${ }^{a}$

\begin{tabular}{cccc}
\hline Entry & Solvents & Time $/ \mathrm{h}$ & ${\text { Yield }(\%)^{b}}^{b}$ \\
\hline 1 & Acetonitrile & 6 & 84 \\
2 & chloroform & 6 & 76 \\
3 & Toluene & 6 & 72 \\
4 & Water & 10 & 65
\end{tabular}

${ }^{a}$ Reaction conditions: benzaldehyde ( $\left.3 \mathrm{mmol}\right), \mathrm{NH}_{4} \mathrm{OAc}(3 \mathrm{mmol})$, ethylacetoacetate $(2 \mathrm{mmol})$, PEG-400 $(0.8 \mathrm{~g})$, solvent $(1 \mathrm{ml})$ under refluxing condition.

${ }^{b}$ Isolated yields.

Experimental General procedure: A mixture of aldehyde (1mmol), $\beta$-di-carbonyl compounds ( $3 \mathrm{mmol})$, ammonium acetate $(3 \mathrm{mmol})$ and PEG400 $(0.8 \mathrm{~g})$ was heated at $100{ }^{\circ} \mathrm{C}$ with stirring for 30-240min. After the completion of reaction as indicated by $\mathrm{TLC}$, the reaction mixture was washed with ice cold water and extracted with Et2O, followed by water and brine solution and dried with anhydrous $\mathrm{Na} 2 \mathrm{SO} 4$. The solution was concentrated in vacuum to afford the crude product. Then, the cure product was purified by recrystallization using ethanol. All compounds were fully characterized by mp, IR, 1H NMR, $13 \mathrm{C}$ NMR spectroscopy. The $(4 \mathrm{i}-4 \mathrm{p})$ data are in full agreement with those previously reported in the literature. $^{7 \mathrm{c}, 7 \mathrm{~d}}$ data.
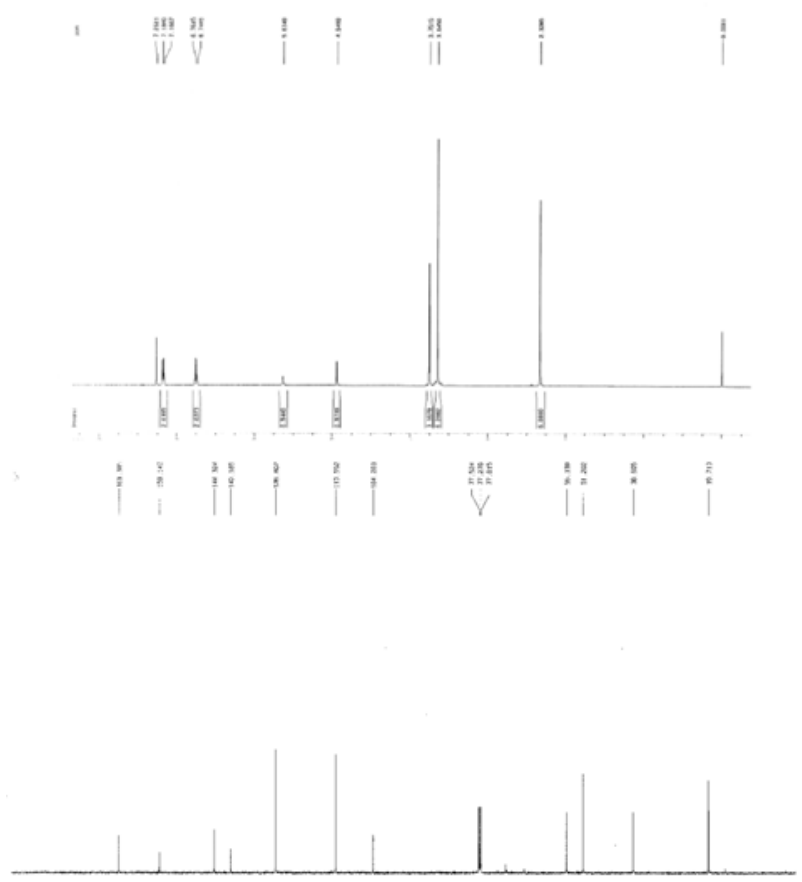

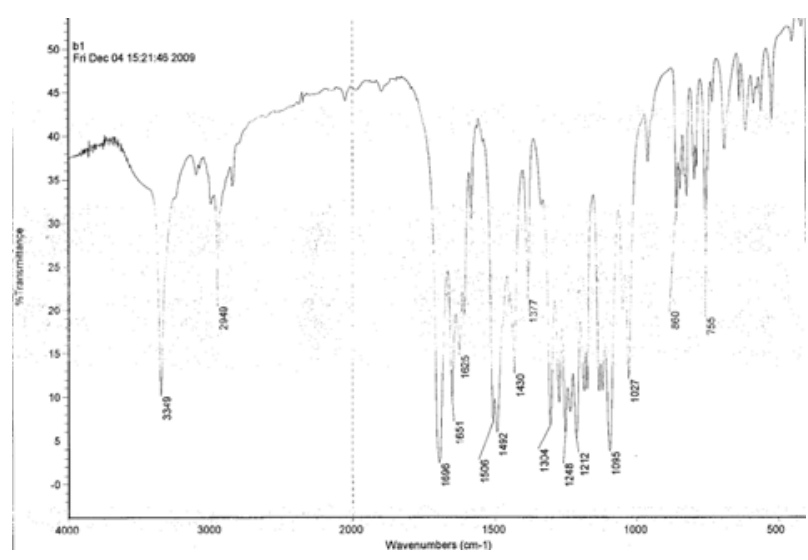

Figure 1. Spectrum of Key compounds $4 \mathrm{~b}$

Dimethyl 4-(4-Methoxyphenyl) -2,6-dimethyl-1,4dihydropyridine-3,5-dicarboxylate(4b) $\mathrm{Mp} 177-179^{\circ} \mathrm{C} .1 \mathrm{H}$ NMR(500MHz, CDCl3): $\delta=2.32(\mathrm{~s}, 6 \mathrm{H}), 3.64(\mathrm{~s}, 6 \mathrm{H})$, $3.75(\mathrm{~s}, 3 \mathrm{H}), 4.94(\mathrm{~s}, 1 \mathrm{H}), 5.63(\mathrm{~s}, 1 \mathrm{H}), 6.75(\mathrm{~d}, \mathrm{~J}=8.7 \mathrm{~Hz}$, $2 \mathrm{H}), 7.17(\mathrm{~d}, \mathrm{~J}=8.65 \mathrm{~Hz}, 2 \mathrm{H}) .13 \mathrm{C} \operatorname{HMR}(125 \mathrm{MHz}$, $\mathrm{CDCl} 3): \delta=19.7,38.6,51.2,55.3,104.2,113.6,128.8$, 140.2, 144.3, 158.1, 168.4. FT-IR(KBr): 3349, 1696, 1651, 1492, 1212, 1095, 755 cm-1(Fig.1.).

III. CONCLUSION

In summary, we have developed the catalyst system consisted of PEG-400/heating for Hantzsch synthesis of 1,4-DHPs under catalyst-free conditions. The environmentally friendliness of PEG medium, chromatogram-free purification process as well as the broad application scope are main advantages of present protocol. This facile and efficient synthetic method should be reasonably useful as complement for those know results on Hantzsch reaction.

\section{ACKNOWLEDGMENT}

Project supported by National Nature Science Foundation of China (No. 41406104)

Natural Science Foundation of Shandong Province (No. ZR2013DQ008)

Science Foundation of Shandong Academy of Science (No.2013QN020)

\section{REFERENCES}

[1] (a) S. Goldman and J. Stoltefuss, Angew. Chem., Int. Ed. Engl. 1991, 30, 1559-1578. (b) H. Nakayama, Y. Kasoaka, Hetercycles, 1996, 42, 901-909.

[2] V.P. Litvinov, Russ. Chem. Bull., 1998, 47, 2053. (a) A.K. Ghosh, G. Bilcer, G. Schiltz, Synthesis, 2001, 2203. (b) B. List, C. Castello, Synlett, 2001, 1687.

[3] (a) R. Shan, C. Velazquez, E.E. Knaus, J. Med. Chem., 2004, 47, 254-261. (b) Y. Sawada, H. Kayakiri, Y. Abe, T. Mizutani, N. Inamura, M. Asano, C. Hatori, I. Arsmori, T. Oku, H. Tanaka, J. Med. Chem., 2004, 47, 2853-2863.

[4] Hilgeroth A.; Lilie, H. Eur. J. Med. Chem., 2003, 38, 495-499.

[5] (a) A. Misral, S. Ganesh, A. Shahiwala, S.P. Shah, J. Pharm. Sci., 2003, 6, 252-273. (b) N. Bodor, P. Buchwald, Drug Discovery Today, 2002, 7, 766-774. (c) L. Prokai, K. Prokai-Tatria, N. Bodor, Med. Res. Rev., 2000, 20, 367-416.

[6] J.P. Wan, Y. Liu, RSC Adv., 2012, 2, 9763-9777.

[7] (a) M. Maheswara, V. Siddaiah, Y.K. Rao, Y.M. Tzeng, C. Sridhar, J. Mol. Catal. A: Chem., 2006, 260, 179-180. (b) G.V.M. Sharma, K.L. Reddy, K. Lakshmi, P.R. Krishna, Synthesis. 2006, 55-58. (c) 
R. Gupta, R. Gupta, S. Paul, A. Loupyb, Synthesis. 2007, 2835 2838. (d) A. Debache, R. Boulcina, A. Belfaitah, S. Rhouati, B. Carboni, synlett. 2008, 509-513. (e) S. Balalae, E. Kowsari, Monatsh. Chem., 2001, 12, 1551. (f) A. Agarval, P.M.S. Chauhan, Tetrahedron Lett., 2005, 46, 1345. (g) S.A. Kotharkar, D. B. Shinde, Ukr. Bioorg. Acta., 2006, 1, 3. (h) M. Li, W.S. Guo, L.R. Wen, Y.F. Li, H.Z. Yang, J. Mol. Catal. A: Chem., 2006, 258, 133. (i) G. Sabitha, G.S. Reddy, C.S. Reddy, J. S. Yadav, Tetrahedron Lett., 2003, 44, 4129. (j) L.M. Wang, J. Sheng, L. Zhang, J.W. Han, Z.Y. Fan, H. Tian, C.T. Qian, Tetrahedron. 2005, 61, 1539. (k) J.L. Donelson, R.A. Gibbs, S.K. De, J. Mol. Catal. A: Chem., 2006, 256, 309. (1) S. Ko, M.N.V. Sastry, C. Lin, C.F. Yao, Tetrahedron Lett., 2005, 46, 5771. (m) M.A. Zolfigol, P. Salehi, A. Khorramabadi-Zad, M. Shayegh, J. Mol. Catal. A: Chem., 2006, 261, 88.(n) M.A. Chari, K. Syamasundar, Catal. Commun., 2005, 6 , 624. (o) S. Ko, C.F. Yao, Tetrahedron. 2006, 62, 7293.
[8] (a) J.M. Harris, S. Zalipsky, Polyethylene Glycol: Chemistry and Biological Application, ACS Books, Washington, D. C., 1997. pp. 489. (b) A. Kamal, D. Reddy, R. Rajendar. Tetrahedron Lett., 2006, 47, 2261-2264. (c) S.L. Jain, S. Singhal, B. Sain, Green Chem., 2007, 9, 740-741. (d) P. Wasserscheid, W. Keim, Angew. Chem., Int. Ed., 2000, 39, 3772-3789. (e) R. Sheldon, Chem. Commun. 2001, 2399-2407. (f) P.A. Grieco, Organic Synthesis in Water, Blackie Academic and Professional, London, 1998, pp. 1-307. (g) R. Breslow, Acc. Chem. Res., 1991, 24, 159-164. (h) S. Chandrasekar, C. Narsihmulu, S.S. Shameem, N.R. Reddy, Chem. Commun., 2003, 1716-1717. (i) K. Tanemura, T. Suzuki, Y. Nishida, T. Horaguchi, Chem. Lett., 2005, 34, 576-577. (j) S.L. Jain, S. Singhal, B. Sain, Green Chem., 2007, 9, 740-741.

[9] T.J. Dickerson, N.N. Reed, K.D. Janda, Chem. Rev., 2002, 102, 3325-3344. 